\title{
A Comparison of Serological and Bacteriological Methods for Detection of Mycloplasma gallisepticum in Experimentally-Infected Chickens
}

\author{
USAMAH AFIFF \\ Department of Infectious Diseases and Veterinary Public Health, Faculty of Veterinary Medicine, \\ Institut Pertanian Bogor, Darmaga Campus, Bogor 16680, Indonesia. \\ Phone: +62-251-8310185, Fax: +62-251-8629466, Email: uafiff@yahoo.co.uk
}

\begin{abstract}
An indirect enzyme-linked immunosorbent assay (ELISA) was developed to detect antibodies to Mycoplasma gallisepticum. Three antigens were used in this experiment. Antigen 1 was prepared from whole cell of $M$. gallisepticum, antigen 2 was a sodium dodecyl sulfatesolubilized preparation from whole cells, and antigen 3 was prepared by sonication of the whole cell antigen. The assay was then used to detect (anti)-M. gallisepticum antibodies in experimentally-infected chickens compared with serum-plate-agglutination (SPA), haemagglutination-inhibition (HI) tests, and tracheal culture. Data obtained in this experiment showed that there was a correlation between seropositivity and rate of isolation of M. gallisepticum. ELISA was found to be less sensitive, but more specific than SPA, and more sensitive than the HI test. The whole cell antigen gave the highest optical densities but was less specific than the other two antigens. The ELISA using all three antigens successfully identified the M. gallisepticum-infected chickens uniformly and positively through 14-35 days post infection, and correctly identified the control group as negative through the 35 day experimental period. The ELISA obviously has a place in the serodiagnosis of avian mycoplasma. Improved-specificity and -sensitivity of the M. gallisepticum antigen is desirable.
\end{abstract}

Key words: serology, detection, Mycoplasma gallisepticum, infected chickens.

The mycoplasmas are the tiniest and simplest prokaryotic cells capable of self replication. The genus Mycoplasma is composed of over 100 species of small prokaryotes (consisting of a genome containing 600-1800 $\mathrm{kb})$. The mycoplasmas are separated from the Eubacteria in the Class Mollicutes ("soft skin") which consist of the single Order Mycoplasmatales. This Order contains six genera (Acheloplasma, Anaeroplasma, Asteroleplasma, Mycoplasma, Spiroplasma, and Ureaplasma) with generic distinctions stand mainly on differences in morphology, genome size and some nutritional requirements (Weisburg et al. 1989). Recently advance techniques have been applied for classification and analysis of the genetic relationships amongst strains of Mycoplasmas such as 16S-rDNA-based technique/amplified-rDNA restriction analysis (Stakenborg et al. 2005), amplified fragment length polymorphism technique (Hong et al. 2005), random amplified polymorphic DNA (RAPD), and pulsed-field gel electrophoresis (PFGE) (Charlton et al. 1999; Mettifogo et al.2006).

Avian mycoplasmosis can be caused by several species of Mycoplasma including Mycoplasma gallisepticum, M. synoviae, M. meleagridis, and M. iowae. M. gallisepticum is the most important pathogen in poultry (Nascimento et al. 2005). M. gallisepticum infection is also known as a chronic respiratory disease (CRD) of chickens (Soeripto 2009). $M$. gallisepticum infection can cause significant economic losses from decreased egg production, reduced feed efficiency, and decreased growth in chicken flocks and other avian species. Infection with $M$. gallisepticum has a wide diversity of clinical manifestation, but even in the absence of apparent clinical signs, the economic impact may be significant (Levisohn and Kleven 2000).

M. gallisepticum infections are transmitted both horizontally and vertically and it remains in the flock constantly as a subclinical form (Bencina et al. 1988;
Feberwee et al. 2005b). M. gallisepticum infection can be diagnosed by clinical manifestation, serology assay, and cultural and biochemical characteristic (Soeripto 2009).

Cultivation techniques used for mycoplasmas are laborious, expensive, and time-consuming, and therefore far from a routine procedure. Problems experienced with culture include overgrowth by faster growing Mycoplasma species (Amin and Jordan 1978).

The objectives of this study were to compare the isolated Mycoplasmas from detection of antibodies from experimentally-infected (EI) chickens with M. gallisepticum and to set up an ELISA test to detect mycoplasma antibodies in serum which would be of practical to use for routine diagnosis in field samples.

\section{MATERIALS AND METHODS}

Experimental Design. Twelve specific-pathogen-free (SPF) White Leghorn chickens at 5 weeks of age were determined to be free of $M$. gallisepticum and M. synoviae by tracheal-culture (Timms 1967) and serology (Avakian et al. 1988) prior to experimental infection. Birds were divided into two groups and caged separately in an isolation house and treated as follows. Each of four birds in first group received $0.2 \mathrm{~mL}$ intratracheally, 1 drop (approximately 50 $\mu \mathrm{L}$ ) by eye-drop, and 1 drop intranasally, of $24 \mathrm{~h}$ broth culture of M. gallisepticum strain S6. Two uninoculated birds were placed in group 1 as contact to infected birds. Group 2 consisted of six uninoculated chickens.

The inoculum was titrated by 10 -fold serial dilution in Eaton's broth just after the chickens were inoculated and was found to contain $2.3 \times 10^{8} \mathrm{CFU} \mathrm{mL}^{-1}$. Chickens in group 1 were bled and tracheal-cultured at weekly intervals starting on day 0 and continuing until the end of the trial on day 35 . Chickens in group 2 were bled and tracheal-cultured at the beginning of the trial (day 0 ) and at the end of the trial (day 35). 
Viable Count. These were performed by the method described by Miles and Misra (1938) with some modifications. Serial tenfold dilution of the cultures were prepared in Eaton's broth, and five $0.02 \mathrm{~mL}$ drops were immediately transferred onto Eaton's agar from each dilution. Plates were incubated at $37^{\circ} \mathrm{C}$ in a moist air tight candle jar for one week before colonies were counted.

For the isolation of mycoplasma, the method described by Timms (1967) was adopted with some modification. Tracheal swabs were inoculated into Eaton's broth and serial dilutions were made to dilute out possible contamination. The culture was incubated at $37^{\circ} \mathrm{C}$ in a candle jar for primary isolation. The culture was checked every $24 \mathrm{~h}$ to detect colour changes in the medium. Changes of colour might indicate growth of the organism. In the case of suspected contamination, filtering was used to remove the contaminant. After incubation for 4 days, the broth cultures were plated onto Eaton's agar and passed onto a second broth, and were then incubated in incubator with a moist $5 \% \mathrm{CO}_{2}$ atmosphere at $37^{\circ} \mathrm{C}$ for 4 days and examined every day. The identification of the Mycoplasma isolates was performed by growth-inhibition tests and the epiimmunofluorescent technique.

Growth Inhibition Test. This test was performed by using Eaton's plates. Plates were divided into two, in which each side was seeded by the running-drop technique. After plates were dried, paper disks which have been saturated with specific antisera to $M$. gallisepticum were placed on top. Then, they were incubated in incubator with a moist $5 \%$ $\mathrm{CO}_{2}$-atmosphere at $37^{\circ} \mathrm{C}$ for $2-3$ days and were then examined for size of zones of growth inhibition.

Epi-Immunofluorescent (EIF) Test Technique. Plates were seeded by the running-drop technique which consists of undiluted and 1 in 100 dilutions of the test sample being dropped onto the same plate. The plates were incubated at $37^{\circ} \mathrm{C}$. Agar blocks with mycoplasma colonies were cut and placed colony side upwards on a slide. For each sample two blocks of agar were cut. One block was treated with specific non-inactivated rabbit antiserum to M. gallisepticum in a dilution of 1:20. The other was treated with antiserum from a mycoplasma of bovine origin, and the block incubated at room temperature for $30 \mathrm{~min}$ in a moist chamber. After incubation, the blocks were tipped into a $10 \mathrm{~mL}$ tube containing approximately $7 \mathrm{~mL}$ of PBS, $\mathrm{pH}$ 7.2-7.4. The tubes were rotated slowly for $10 \mathrm{~min}$ and then the PBS was decanted, replaced by fresh PBS, and the tubes were again rotated for $10 \mathrm{~min}$. The PBS was gently decanted and the block tipped out onto a slide and placed colony-side upwards. Each block was flooded with anti-rabbit IgG antiserum conjugated with FITC in a dilution of 1:10. The blocks were again incubated for $30 \mathrm{~min}$ at room temperature in a moist chamber. After incubation the blocks were washed twice as before, using rotation. The blocks were examined under a fluorescence microscope.

Antigen Preparation. To prepare antigen, approximately $10 \mathrm{~mL}$ of Eaton's was inoculated with M. gallisepticum. This volume was used to inoculate $100 \mathrm{~mL}$ of Eaton's broth which was incubated for $24 \mathrm{~h}$ at $37^{\circ} \mathrm{C}$. Each $100 \mathrm{~mL}$ aliquot was then used to inoculate $1000 \mathrm{~mL}$ of Eaton's broth which was incubated for $24 \mathrm{~h}$ in air at $37^{\circ} \mathrm{C}$. The culture was then stirred gently and continuously. Three different antigenic treatments were performed, i.e. wholecell antigen, sonicated- and SDS-solubilized antigens. The whole cell was harvested by centrifugation at $12000 \mathrm{x}$ g for $30 \mathrm{~min}$ at $4^{\circ} \mathrm{C}$. It was resuspended in PBS (pH 7.2) and recentrifuged three times. The final pellet was resuspended in sterile PBS to give a final concentration of $5 \mathrm{mg}$ protein $\mathrm{mL}^{-1}$ and stored at $-70^{\circ} \mathrm{C}$ in a small volume (aliquot). This was used as whole cell antigen. Three $\mathrm{mL}$ of $M$. gallisepticum whole cell antigen were sonicated for $10 \mathrm{~min}$, $30 \mathrm{sec}$ on and $30 \mathrm{sec}$ off. This was used as sonicated antigen. For the preparation of SDS-solubilized antigen, the method described by Talkington et al. (1984) was adopted. M. gallisepticum-whole-cell-antigen was diluted to give a final concentration of $1 \mathrm{mg}$ protein $\mathrm{mL}^{-1}$ and incubated with $1 \%$ SDS ( $1 \mathrm{mg} \mathrm{SDS} \mathrm{mg}{ }^{-1}$ protein) for $90 \mathrm{~min}$ at $37^{\circ} \mathrm{C}$, and centrifuged at $20000 \mathrm{~g}$ for $30 \mathrm{~min}$ at $4^{\circ} \mathrm{C}$. The supernatant was then removed and stored at $4{ }^{\circ} \mathrm{C}$ and used within $2 \mathrm{wk}$.

Determination of Protein Concentration. The protein concentration was determined by the BCA protein assay (Pierce Laboratories, Rockford, USA) as directed by the manufacturer. The substrate was prepared by dissolving $5 \mathrm{mg}$ of P-nitrophenyl phosphate (Sigma, 1 tablet) in $5 \mathrm{~mL}$ freshly made substrate buffer.

The Indirect ELISA Procedure. For the ELISA, the method described by Talkington et al. (1984) was adopted. The antigen was diluted in coating buffer and $100 \mu \mathrm{L}$ of the mixture was dispensed into each well (Nunc-immuno microtitre plate, polysorp F16, Inter Med-Denmark) except for wells in rows A and B. The plates were incubated for $2 \mathrm{~h}$ at $37^{\circ} \mathrm{C}$. After incubation the plates were washed 5 times in washing solution using a commercial washer (Dynatech). Washing was done twice and in between washes the plates were filled with washing solution for $1 \mathrm{~min}$. One hundred micro litre aliquot of diluted serum was placed onto the test microtitre plate and incubated at $37^{\circ} \mathrm{C}$ for $30 \mathrm{~min}$. After incubation the plates were washed as in step 2 and $100 \mu \mathrm{L}$ of conjugate was then added. The plates were incubated for 30 $\min$ at $37^{\circ} \mathrm{C}$. After incubation the plates were then washed as in step $2,100 \mu \mathrm{L}$ of substrate was then added. The plates were incubated at $37^{\circ} \mathrm{C}$ for $30 \mathrm{~min}$ and read on an ELISA reader (Dynatech MR500) at approximately $410 \mathrm{~nm}$. Before the addition of conjugate, $100 \mu \mathrm{L}$ of monoclonal antibody to IgM was placed onto the test microtitre plate and incubated at $37^{\circ} \mathrm{C}$ for $30 \mathrm{~min}$. This was conducted for detection of immunoglobulin $\mathrm{M}$ (IgM). As baseline for ELISA, values indicating at which point a result was positive or negative were established using 60 sera from chickens known to be mycoplasma-free. Both antigen and sera were diluted 1:400 and the conjugate 1:2000. The test was carried out as described earlier. The baseline value was then interpreted as the average of these 60 values plus 4 standard deviation values above their mean. A checkerboard titration was carried out to determine the working dilutions of antiserum 
and antigens. Two-fold serial dilutions of the antiserum and antigen were made in the diluting medium. The conjugate was diluted 1:2000. The test was carried out as the same procedure as before.

Specificity Tests. These were done using antisera to different mycoplasma. The antisera were first treated so as to remove the anti-medium component in order to minimize cross-reactions. Rabbit anti-sera against M. gallisepticum, M. synoviae, and M. meleagridis were used. One-way crossreactivity was done using antisera obtained from experimentally (EI) and contact-infected (CI) chickens tested with whole cell M. synoviae antigen in SPA test, HI test, and ELISA.

Treatment of Sera to Minimize Cross-Reactions. The rabbit sera were diluted 1:10 in Eaton's broth and incubated for $30 \mathrm{~min}$ at $37^{\circ} \mathrm{C}$. They were then centrifuged once at $20000 \mathrm{x}$ g and the floating layer of fat was removed. Both sera (treated and untreated) and antigen was diluted 1:200 and the test was carried out as described earlier.

Sensitivity Tests. These were done using antisera obtained from EI chickens at 35 days. Two-fold dilution of the antiserum from 1:100 to 1:55 200 were made. Antigen was diluted 1:400 and the conjugate was diluted 1:2000.

Haemagglutination Inhibition (HI) Test. For the HI test the method described by Timms (1967) was adopted. Using PBS, 200 Laliquot of serial two-fold antigen dilution were prepared in a WHO agglutination plate. To each dilution 200 L of PBS and 1\% chicken red blood cells were added, giving a total of $600 \mathrm{~L}$ in each well. An RBC control consisting of 400 L PBS and 200 L of 1\% chicken red blood cells was placed in the last well. The plate was shaken to ensure thorough mixing and readings were made after 50 min at room temperature.

Haemagglutination Inhibition (HI) Procedure. Using wells A an initial 1:5 dilution was prepared from each test serum (i.e. $25 \mu \mathrm{L}$ of serum $+100 \mu \mathrm{L}$ PBS). $25 \mu \mathrm{L}$ of this dilution was transferred to wells $\mathrm{H}$ and G. $25 \mu \mathrm{L}$ of PBS was placed in wells $G$ to $B$ and serial two-fold dilutions were prepared, discarding the final $25 \mu \mathrm{L}$ from well B at the end of the titration. Fifty micro litre of the 1:5 serum dilution was discarded from well A, leaving $25 \mu \mathrm{L}$ for provision of a serum control. Then, $25 \mu \mathrm{L}$ of $4 \mathrm{HA}$ antigen was added to wells $\mathrm{H}$ to $\mathrm{B}$. In place of antigen, $25 \mu \mathrm{L}$ of PBS was added to well A. Twenty five micro litre of $1 \%$ chicken RBC's was added to wells $\mathrm{H}$ to $\mathrm{A}$, thus bringing the total volume in each well to $75 \mu \mathrm{L}$. Controls treatments included were: test serum control, known positive and negative control sera, antigen control and RBC control. In order to ensure freedom from "non-specific" agglutination, $25 \mu \mathrm{L}$ of 1:5 serum dilution, PBS and $1 \%$ RBC were placed at the end of each titration (i.e. in well A), and it was used as test serum control. Known positive and negative control sera were tested in the same manner. Antigen control: at the end of each assay (Row 12), the HA activity of the antigen was checked, using the same technique as previously described for "antigen preparation", but with $25 \mu \mathrm{L}$ volumes in place of 200 L. The last well of the plate (A12) was used to check that the RBC's button down clearly without signs of haemolysis or non-specific agglutination $(25 \mu \mathrm{L}$ of $1 \%$ RBC's and $50 \mu \mathrm{L}$ of PBS), and this was used as RBC control. The plate was shaken lightly to ensure thorough mixing of the well contents and read after $50 \mathrm{~min}$ at room temperature, or when the antigen titration was reading exactly 4HA. Interpretation of the HI method: HI titres of 5 and above were considered positive.

Serum Plate Agglutination. For serum plate agglutination the method described by Timms (1967) was adopted. Stained antigen was allowed to warm up to room temperature and shaken well before use. Twenty five litre of serum and stained antigen were placed on ceramic tiles and were mixed well with a clean glass or plastic rod. Known positive and negative sera were included and tested in the same manner. Ceramic tiles were rocked gently for $2 \mathrm{~min}$.

\section{RESULTS}

At weekly intervals, starting at day 0 and continuing until day 28, all chickens were examined for the presence of Mycoplasma species by tracheal culture. At the end of the trials, all chickens were killed and their air-sacs, trachea and lungs were collected for mycoplasma isolation. Isolated myco-plasma were identified to the species level by epiimmunofluorescent technique and growth inhibition test, and only the Mycoplasma species used for inoculation was recovered.

For determination of the optimum antigen and serum dilution, known positive and negative chicken sera to $M$. gallisepticum at various dilutions were titrated against various dilutions of antigen using checker-board design procedure. M. gallisepticum antigen was tested at 1:100, $1: 200,1: 400$, and 1:800 dilutions against 1:100, 1:200, 1:400 serum dilutions, and alkaline phosphatase conjugate at 1:2000 dilutions was used. Fig 1a, 1b, and 1c showed the optical density values obtained in checker-board titration of whole cell, sonicated-, and SDS-solubilized antigen, respectively from which the working dilution of antigen and serum were calculated. The optimum antigen and serum dilution for whole cell antigen was 1:400 (Fig 1a). The optimum antigen and serum dilution for SDS-solubilized and sonicated antigen was 1:400 for the antigen and 1:200 for serum (Fig $1 \mathrm{~b}$ and 1c). However when these dilutions were applied with sera obtained from EI chickens they gave a high background. Therefore some adjustment was necessary, resulting in the choice of a 1:400 dilution for both antigen and serum.

Baseline values, indicating at which point a result was positive or negative, were established using 60 negative chicken sera known to be mycoplasma-free (SPF chickens of mycoplasmosis). The result showed the mean value of absorbance was $0.102 \pm 0.038$. The baseline value was fixed at absorbance $+4 \mathrm{SD}$ (equal to 0.255 ) for $30 \mathrm{~min}$ substrate reaction time at $410 \mathrm{~nm}$.

In the EI chickens, the SPA test showed no activity at 0 days post infection. By 7-35 days post infection, 100\% of the samples were positive to $M$. gallisepticum. In the CI 

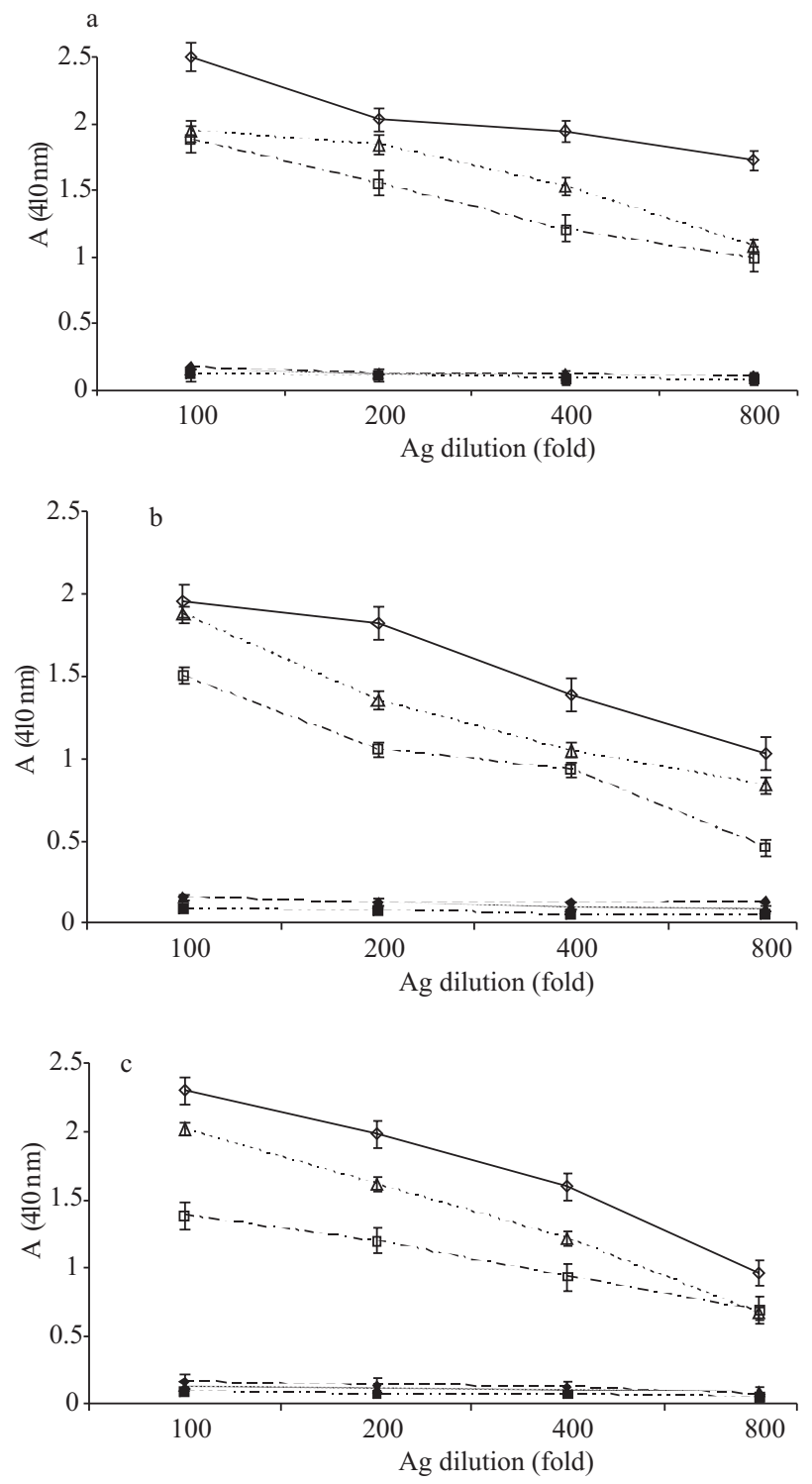

Fig 1 Determination of optimum antigen (ag) dilution of Mycoplasma gallisepticum at conjugate dilution 1:2000: a, whole cell antigen; b, sonicated antigen; c, SDS-solubilized antigen. $\diamond, 100$ fold diluted + sera; $\diamond$, 100 fold diluted sera; $\Delta, 200$ fold diluted + sera; $\boldsymbol{\Lambda}, 200$ fold diluted sera; $\square$, 400 fold diluted + sera; $\mathbf{m}, 400$ fold diluted sera; + sera, known positive chicken sera to $M$. gallisepticum; -sera, known negative SPF chicken sera to M. gallisepticum. chickens the SPA test showed no activity at 0-14 days postinfection and by 21-35 days post-infection, $100 \%$ of the samples were positive. In the EI chickens the HI test had no activity until 7 days post-infection and $100 \%$ were positive at 14 through 35 days post-infection. In the CI chickens the HI test showed no activity at 21 days post-infection, and $100 \%$ were positive at 28 to 35 days post-infection. In the EI chickens, $75 \%$ of the samples were positive at 7 days post-infection with ELISA using whole cell, SDSsolubilized and sonicated antigen, and $100 \%$ were positive by 14 days post-infection (Table 1 ).

At 7-35 days post infection $M$. gallisepticum was recovered from all EI chickens, and at day 21 post infection M. gallisepticum was recovered from 1 of 2 CI chickens, and by days 21-35 days post infection $M$. gallisepticum was recovered from all CI chickens. Thus, in comparing serological and bacteriological methods, the SPA test and tracheal-culture were the most sensitive, and the HI test the least sensitive assay. ELISA was less sensitive than the SPA test and tracheal-culture, but more sensitive than the HI test (Table 1).

Fig 2 shows absorption (A $410 \mathrm{~nm}$ ) values of whole cell, SDS-solubilized and sonicated antigen of M gallisepticum in

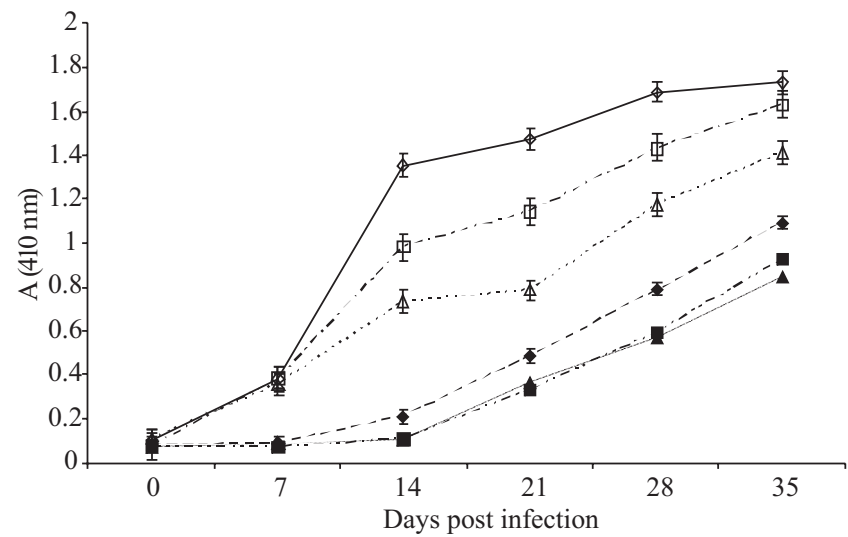

Fig 2 Development of immunoglobulin $\mathrm{G}$ ( $\mathrm{IgG}$ ) antibodies in experimentally-infected (EI) and contact-infected (CI) chickens with Mycoplasma gallisepticum strain S6 detected by ELISA. $\diamond$, EI whole cell antigen; $\bullet$ CI whole cell antigen; $\Delta$, EI SDS-solubilized antigen; $\boldsymbol{\Delta}, \mathrm{CI}$ SDS-solubilized antigen; $\square$, EI sonicated antigen; $\mathbf{\bullet}$, CI sonicated antigen.

Table 1 Comparison of SPA test, HI test, ELISA, and tracheal-culture for detection of Mycoplasma gallasepticum infection in experimentally-infected chickens (EI) and contact-infected chickens (CI)

\begin{tabular}{|c|c|c|c|c|c|c|c|c|c|c|c|c|}
\hline \multirow{2}{*}{$\begin{array}{l}\text { Days } \\
\text { post } \\
\text { infect } \\
\text { ion }\end{array}$} & \multicolumn{2}{|c|}{ SPA test } & \multicolumn{2}{|c|}{ HI test } & \multicolumn{2}{|c|}{ ELISA $^{\mathrm{A}}$} & \multicolumn{2}{|c|}{ ELISA $^{\mathrm{B}}$} & \multicolumn{2}{|c|}{ ELISA $^{\mathrm{C}}$} & \multicolumn{2}{|c|}{ Tracheal- culture } \\
\hline & EI & $\mathrm{CI}$ & EI & $\mathrm{CI}$ & $\begin{array}{l}\text { EI } \\
\text { ( Po }\end{array}$ & $\begin{array}{c}\text { CI } \\
\text { sampl }\end{array}$ & EI & $\mathrm{CI}$ & EI & $\mathrm{CI}$ & EI & $\mathrm{CI}$ \\
\hline 0 & $0 / 4$ & $0 / 2$ & $0 / 4$ & $0 / 2$ & $0 / 4$ & $0 / 2$ & $0 / 1$ & $0 / 2$ & $0 / 4$ & $0 / 2$ & $0 / 4$ & $0 / 2$ \\
\hline 7 & $4 / 4$ & $0 / 2$ & $0 / 4$ & $0 / 2$ & $3 / 4$ & $0 / 2$ & $3 / 4$ & $0 / 2$ & $3 / 4$ & $0 / 2$ & $4 / 4$ & $0 / 2$ \\
\hline 24 & $4 / 4$ & $0 / 2$ & $4 / 4$ & $0 / 2$ & $4 / 4$ & $0 / 2$ & $4 / 4$ & $0 / 2$ & $4 / 4$ & $0 / 2$ & $4 / 4$ & $0 / 2$ \\
\hline 21 & $4 / 4$ & $2 / 2$ & $4 / 4$ & $0 / 2$ & $4 / 4$ & $2 / 2$ & $4 / 4$ & $2 / 2$ & $4 / 4$ & $2 / 2$ & $4 / 4$ & $2 / 2$ \\
\hline 28 & $4 / 4$ & $2 / 2$ & $4 / 4$ & $2 / 2$ & $4 / 4$ & $2 / 2$ & $4 / 4$ & $2 / 2$ & $4 / 4$ & $2 / 2$ & $4 / 4$ & $2 / 2$ \\
\hline 35 & $4 / 4$ & $2 / 2$ & $4 / 4$ & $2 / 2$ & $4 / 4$ & $2 / 2$ & $4 / 4$ & $2 / 2$ & $4 / 4$ & $2 / 2$ & $4 / 4$ & $2 / 2$ \\
\hline
\end{tabular}


detecting anti-M gallisepticum antibodies in EI chickens and CI chickens. It was observed that the whole cell antigen gave the highest absorbance value and SDS-solubilized antigen gave the lowest.

The sensitivity between ELISA and the HI test using sera obtained at 35 days post infection was compared (Table 2). Serum was diluted starting 1:100 and using 2-fold dilution to 1:51,200. It was observed that the ELISA was more sensitive than the HI test.

Absorbance values of cross-reaction test between whole cell, SDS-solubilized, and sonicated antigens with treated and untreated $M$. synoviae and $M$. meleagridis antisera prepared in rabbits were compared (Table 3). Whole cell antigen gave highest optical densities both with treated and untreated antisera to $M$. meleagridis. SDS-solubilized and sonicated antigen gave high absorbance with untreated antisera, but gave low absorbance with treated antisera. Thus SDS-solubilized and sonicated antigens were more specific than whole cell antigen.

Table 4 compares the one-way cross-reactivity of the SPA test, HI test and ELISA, using a M. gallisepticum antiserum obtained from EI and CI chickens. The SPA test had the highest incidence of cross-reactivity, by 28 days post infection, all the samples were reacting non-specifically in the agglutination test. The HI test showed no cross-reaction. ELISA using sera obtained form EI chickens at 14 and 21 days post-infection showed a high incidence of crossreaction, but by day 35 post-infection there was no indication of cross-reactivity by ELISA. ELISA using sera from CI chickens showed no cross-reaction. Therefore ELISA was more specific than SPA, but less specific than the HI test.

The development of immunoglobulin $\mathrm{G}(\mathrm{IgG})$ in EI and CI chickens detected by ELISA using different preparations of antigen showed that the whole cell antigen gave a higher result than SDS-solubilized and sonicated antigen. All
Table 3 Absorbance values of cross-reaction test obtained in ELISA using untreated and treated rabbit anti-sera to Mycoplasma gallisepticum, M. synoviae, and M. meleagridis with $M$. gallisepticum antigens

\begin{tabular}{|c|c|c|c|c|c|c|}
\hline \multirow{3}{*}{ Antigen } & \multicolumn{6}{|c|}{ Antisera } \\
\hline & \multicolumn{2}{|c|}{$M g$} & \multicolumn{2}{|c|}{$M s$} & \multicolumn{2}{|c|}{$M m$} \\
\hline & untreated & treated & untreated & treated & untreated & treated \\
\hline WC & 1.500 & 0.973 & 0.651 & 0.267 & 0.343 & 0.032 \\
\hline SS & 1.362 & 0.762 & 0.290 & 0.158 & 0.294 & 0.030 \\
\hline S & 0.974 & 0.597 & 0.326 & 0.236 & 0.113 & 0.027 \\
\hline
\end{tabular}

For ELISA untreated: antigen and serum dilution of 1:400 dilution was used; for ELISA treated: treated sera and antigen were diluted 1:200, Rabbit anti-M. gallisepticum, M. synoviae, and M. meleagridis sera were used. $\mathrm{Mg}$, M. gallisepticum; Ms, M. synoviae; Mm, M. meleagridis; WC, whole cell antigen; SS, SDS-solubilized antigen; S, sonicated antigen.

Table 4 Comparison of serum plate agglutination (SPA), Haemagglutination inhibition (HI) test, and ELISA : cross-reactivity of Mycoplasma gallisepticum antisera obtained from experimentally infected (EI) chickens and contact-infected (CI) chickens with Mycoplasma synoviae antigens

\begin{tabular}{|c|c|c|c|c|c|c|}
\hline \multirow{3}{*}{$\begin{array}{l}\text { Day post } \\
\text { Infection }\end{array}$} & \multicolumn{2}{|c|}{ SPA test } & \multicolumn{2}{|c|}{ HI test } & \multicolumn{2}{|c|}{ ELISA } \\
\hline & EI & $\mathrm{CI}$ & EI & $\mathrm{CI}$ & EI & $\mathrm{CI}$ \\
\hline & \multicolumn{6}{|c|}{ ( Positive sample /tested sample) } \\
\hline 0 & $0 / 4$ & $0 / 2$ & $0 / 4$ & $0 / 2$ & $0 / 4$ & $0 / 2$ \\
\hline 7 & $2 / 4$ & $0 / 2$ & $0 / 4$ & $0 / 2$ & $0 / 4$ & $0 / 2$ \\
\hline 14 & $2 / 4$ & $0 / 2$ & $0 / 4$ & $0 / 2$ & $0 / 4$ & $0 / 2$ \\
\hline 21 & $3 / 4$ & $1 / 2$ & $0 / 4$ & $0 / 2$ & $3 / 4$ & $0 / 2$ \\
\hline 28 & $4 / 4$ & $2 / 2$ & $0 / 4$ & $0 / 2$ & $3 / 4$ & $0 / 2$ \\
\hline 35 & $4 / 4$ & $2 / 2$ & $0 / 4$ & $0 / 2$ & $0 / 4$ & $0 / 2$ \\
\hline
\end{tabular}

EI, chicken were inoculated intratracheally, intranasally, and by eyedrop with approximately $2.3 \times 10^{8}$ colony forming units per $\mathrm{mL}$ of $24 \mathrm{~h}$ broth culture M.gallasepticum strain S6. CI, uninoculated chicken placed in the same cage with inoculated chickens. Positive sample/tested sample, number of positive samples/ number of samples tested. For HI tests positives values $\geq 5 \mathrm{HI}$ titre; for ELISA positive values absorbance at (410 $\mathrm{nm}) \geq 0.255$.

Table 2 Sensitivity of the ELISA ${ }^{\text {and }}$ HI test (HIT) with sera from chickens experimentally-infected (EI) with Mycoplasma gallisepticum strain S6 and with sera from contact-infected (CI) chickens obtained at 35 days post infection.

\begin{tabular}{|c|c|c|c|c|c|c|c|c|}
\hline \multirow[t]{3}{*}{ Serum dilution } & \multicolumn{2}{|c|}{ HIT } & \multicolumn{2}{|c|}{ ELISA $^{\mathrm{A}}$} & \multicolumn{2}{|c|}{ ELISA $^{\mathrm{B}}$} & \multicolumn{2}{|c|}{ ELISA $^{\mathrm{C}}$} \\
\hline & EI & $\mathrm{CI}$ & EI & $\mathrm{CI}$ & EI & $\mathrm{CI}$ & EI & $\mathrm{CI}$ \\
\hline & \multicolumn{8}{|c|}{ (Positive sample/tested sample) } \\
\hline 100 & $4 / 4$ & $0 / 2$ & $4 / 4$ & $2 / 2$ & $4 / 4$ & $2 / 2$ & $4 / 4$ & $2 / 2$ \\
\hline 200 & $4 / 4$ & $0 / 2$ & $4 / 4$ & $2 / 2$ & $4 / 4$ & $2 / 2$ & $4 / 4$ & $2 / 2$ \\
\hline 400 & $4 / 4$ & $0 / 2$ & $4 / 4$ & $2 / 2$ & $4 / 4$ & $2 / 2$ & $4 / 4$ & $2 / 2$ \\
\hline 800 & $0 / 4$ & $0 / 2$ & $4 / 4$ & $2 / 2$ & $4 / 4$ & $2 / 2$ & $4 / 4$ & $2 / 2$ \\
\hline 1600 & $0 / 4$ & $0 / 2$ & $4 / 4$ & $0 / 2$ & $4 / 4$ & $0 / 2$ & $4 / 4$ & $1 / 2$ \\
\hline 3200 & $0 / 4$ & $0 / 2$ & $4 / 4$ & $0 / 2$ & $4 / 4$ & $0 / 2$ & $4 / 4$ & $0 / 2$ \\
\hline 6400 & $0 / 4$ & $0 / 2$ & $4 / 4$ & $0 / 2$ & $3 / 4$ & $0 / 2$ & $4 / 4$ & $0 / 2$ \\
\hline 12800 & $0 / 4$ & $0 / 2$ & $4 / 4$ & $0 / 2$ & $0 / 4$ & $0 / 2$ & " & $0 / 2$ \\
\hline 25600 & $0 / 4$ & $0 / 2$ & $0 / 4$ & $0 / 2$ & $0 / 4$ & $0 / 2$ & $0 / 4$ & $0 / 2$ \\
\hline 51200 & $0 / 4$ & $0 / 2$ & $0 / 4$ & $0 / 2$ & $0 / 4$ & $0 / 2$ & $0 / 4$ & $0 / 2$ \\
\hline
\end{tabular}

Antigen dilution 1:400 and conjugate dilution 1:2000. EI, chicken were inoculated intratracheally, intranasally, and by eyedrop with approximately $2.3 \mathrm{x}$ $10^{8}$ colony forming units per $\mathrm{mL}$ of $24 \mathrm{~h}$ broth culture $M$. gallasepticum strain S6. CI, uninoculated chicken placed in the same cage with inoculated chickens. Positive sample/tested sample, number of positive samples/ number of samples tested. For HI tests positives values $\geq 5$ HI titre; for ELISA, positive values absorbance at $(410 \mathrm{~nm}) \geq 0.255$. A, tested with whole cell antigen; B, tested with SDS-solubilized antigen; C, tested with sonicated antigen. 
Table 5 Development of immunoglobulin G (IgG) antibodies in experimentally infected (EI) chickens and contact-infected (CI) chickens, detected by ELISA

\begin{tabular}{|c|c|c|c|c|c|c|}
\hline \multirow{2}{*}{$\begin{array}{c}\text { Days } \\
\text { post } \\
\text { infection }\end{array}$} & \multicolumn{2}{|c|}{ ELISA $^{\mathrm{A}}$} & \multicolumn{2}{|c|}{ ELISA $^{\mathrm{B}}$} & \multicolumn{2}{|c|}{ ELISA $^{\mathrm{C}}$} \\
\hline & EI & CI & EI & CI & EI & CI \\
\hline 0 & 0.104 & 0.082 & 0.106 & 0.070 & 0.075 & 0.070 \\
\hline 7 & 0.386 & 0.088 & 0.355 & 0.080 & 0.381 & 0.073 \\
\hline 14 & 1.356 & 0.221 & 0.734 & 0.103 & 0.981 & 0.111 \\
\hline 21 & 1.473 & 0.485 & 0.783 & 0.363 & 1.143 & 0.355 \\
\hline 28 & 1.690 & 0.879 & 1.176 & 0.567 & 1.433 & 0.596 \\
\hline 35 & 1.731 & 1.045 & 1.414 & 0.841 & 1.631 & 0.925 \\
\hline
\end{tabular}

EI, chicken were inoculated intratracheally, intranasally and by eyedrop with approximately $2.3 \times 10^{8}$ colony forming units per $\mathrm{ml}$ of $24 \mathrm{~h}$ broth culture Mycoplasma gallasepticum strain S6. CI, uninoculated chicken placed in the same cage with inoculated chickens. LLISA $^{\mathrm{A}}$ : Mean absorbance $\left(\mathrm{A}_{410 \mathrm{~mm}}\right)$, obtained in ELISA, using whole cell antigen. ELISA ${ }^{\mathrm{B}}$ : Mean absorbance $\left(\mathrm{A}_{410} \mathrm{~nm}\right)$, obtained in ELISA, using SDS-solubilized antigen. ELISA ${ }^{\mathrm{C}}$ : Mean absorbance $\left(\mathrm{A}_{410} \mathrm{~nm}\right)$, obtained in ELISA, using sonicated antigen.

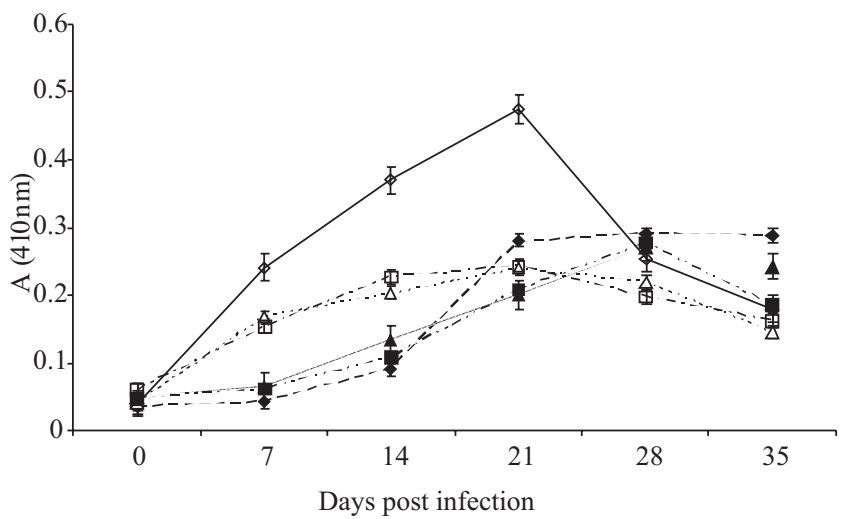

Fig 3 Development of immunoglobulin $\mathrm{M}$ (IgM) antibodies in experimentally-infected (EI) and contact-infected (CI) chickens with Mycoplasma gallisepticum strain S6 detected by ELISA. $\diamond$, EI whole cell antigen; $\diamond$, CI whole cell antigen; $\Delta$, EI SDS-solubilized antigen; $\boldsymbol{\Delta}, \mathrm{CI}$ SDS-solubilized antigen; $\square$, EI sonicated antigen; $\mathbf{n}$, CI sonicated antigen.

antigen was first detected the $\operatorname{IgG}$ by day 7 post-infection in EI chickens, and by day 21 in CI chickens (Table 5).

The development of immunoglobulin $\mathrm{M}(\operatorname{IgM})$ in EI and CI chickens detected by ELISA of whole-cell, SDSsolubilized, and sonicated antigen were compared. The wholecell antigen gave the highest result. In EI chickens IgM titres increased from day 7 to day 21 post-infection and decreased from day 28 to day 35 post-infection. In EI chickens IgM titres increased from day 7 to day 21 post-infection and decreased from day 28 to day 35 post-infection (Fig 3 ).

\section{DISCUSSION}

Serum plate agglutination, ELISA and tracheal-culture can detect M. gallisepticum infection in EI chickens by day 7 post-infection, and by day 21 in CI chickens. Data obtained in these experiments showed there is correlation between seropositivity and the rate of isolation of $M$. gallisepticum. Thus serum-plate-agglutination and ELISA were effective in identifying $M$. gallisepticum infection in EI and CI chickens. These data suggest that serum plate agglutination and ELISA can identify culture positive chickens, but the rate of isolation of $M$. gallisepticum from field material does not always correlate with seropositivity (Salami et al. 1992). These authors reported that mycoplasma could not be isolated from several seropositive birds; in addition Fritz et al. (1992) reported that only a small number of $M$. gallisepticum and M. synoviae was isolated from serologically-positive wild turkeys. Feberwee et al. (2005a) found in their study that a certain level of false positive results can be expected in any serological test. Isolation of avian mycoplasma from field material is influenced by several factors. According to Amin and Jordan (1978) these factors can be classified into two main groups. First, those associated with the organs and tissues of the host, such as the duration of infection, intercurrent infection with other avian pathogens, the presence of competing flora, especially fast growing mycoplasma, transfer and treatment of tissue. Second, those associated with the provision of growth requirements, such as the components, form and $\mathrm{pH}$ of the medium, temperature and humidity of incubation.

The serum-plate agglutination and haemagglutination tests have been used for many years to diagnose $M$. gallisepticum infection. The non-specific reaction which occurs with the serum plate agglutination test makes it necessary to resort to the haemagglutination-inhibition test to confirm a diagnosis (Patten et al. 1984). However the haemagglutination inhibition test lacks sensitivity, especially in early stages of infection, and certain strains of M. gallisepticum appear incapable of eliciting a response which can be detected by the haemagglutination test (Sahy and Olsen 1981). Thus a more sensitive and specific assay is needed. The ELISA is a sensitive test which could overcome some deficiencies of the other tests. However, one of the main disadvantages has been the appearance of crossreactivity between $M$. gallisepticum and $M$. synoviae (Talkington et al. 1984) and false positive reactions with negative sera (Jordan and Mustafa 1983).

Three different preparations of antigen, whole cell, SDSsolubilized, and sonicated antigen were used in these experiment. Both SDS-solubilized and sonicated antigen gave lower absorbance than the whole cell antigen. It can only be assumed that sonication breaks down the protein to peptides that are not recognized by the antibody and also sonication generated heat that can denature the protein causing changes in its conformation.

To determine whether an absorbance value was positive or negative, fixed baseline values were calculated using wholecell antigen as a standard, a threshold absorbance value of mean \pm 4SD (0.255) were chosen. This caused a loss of sensitivity but was necessary in order to maintain specificity.

The performance of ELISA was assessed by comparison with the SPA and HI test. When compared with the HI test, ELISA proved sensitive. ELISA successfully confirmed $75 \%$ of $M$. gallisepticum-infected chickens as positive by day 7 post infection, and by days 14 to 35 post infection ELISA successfully confirmed $100 \%$ of M. gallisepticuminfected chickens. In the comparison, HI test showed no activity until day 7 post-infection and by days 14 to 35 , the HI test gave positive results with all infected chickens. This 
may be because the HI test detected antibody in the 7S IgG class, which normally does not appear until approximately 2 weeks after primary exposure (Roberts and Olesiuk 1967). Although it was less sensitive than ELISA, the HI test was much more specific. When compared with the SPA test, ELISA was much more specific, but less sensitive. However, because the SPA test measures IgM antibodies and ELISA primarily measure IgG antibodies, although light-chain cross-reactivity is possible. It is therefore difficult to effectively compare the sensitivities of these assays.

Many of the false positive reactions in the ELISA have been correlated prior to inoculation of poultry with commercial fowl coryza (Haemophilus paragallinarum) bacteria, also inactivated infectious bursal disease virus vaccine produce strong systemic antibody responses to components of mammalian sera (Avakian and Kleven 1990). It is known that serum components from the growth medium become associated with the M. gallisepticum cell during in vitro growth (Thorn and Boughton 1980). It is suggested that these associated medium components contribute significantly to false positives in M. gallisepticum serology. Timms and Cullen (1974) suggested that the presence of rheumatoid factor in chicken sera was a cause of false positive reactions, and Ansari et al. (1982) suggested a common mycoplasma antigen exists between $M$. gallisepticum and M. synoviae because of the extreme sensitivity of ELISA. In these experiments SDS-solubilized antigen was more specific than sonicated- and whole cellantigen, it may be because solubilization with SDS causes a removal of common antigen (Higgins and Whithear 1985).

Avakian and Kleven (1990) suggested that purified antigen would be necessary to develop more specific ELISA. Serology tests are particularly helpful in screening poultry flock. It is important to know the mycoplasma infection status of poultry flock, as this will influence decisions related to use of antibiotics, vaccination programme and biosecurity planning.

Immunological responses of $M$. gallisepticum-infected chickens, can be followed by quantification of IgG and/or IgM concentrations. This technique is nowadays widely applied for diseases control in mycoplasmosis. The concentrations of $\mathrm{IgG}$ and/or IgM are be measured prior to and post challenges. The effectiveness of MG vaccines are compared between serological responses of vaccinated groups to control animals are given by Gatesa et al. (2008).

\section{REFERENCES}

Amin MM, Jordan FTW. 1978. A comparative study of some cultural methods in the isolation of avian mycoplasma from field material. Avian Pathol 7:455-70.

Ansari AA, Taylor RF, Chang TS. 1982. Application of enzyme-linked immunosorbent assay for detecting antibody to M. gallisepticum infection in poultry. Avian Dis 27:21-35.

Avakian AP, Kleven SH. 1990. The humoral immune response of chickens to Mycoplasma gallisepticum and Mycoplasma synoviae studied by immunoblotting. Vet Microbiol 24:155-69.

Avakian AP, Kleven SH, Glisson JR. 1988. Evaluation of the specificity and sensitivity of two commercial enzyme-linked immunosorbent asay kits the serum plate agglutination test and the hemagglutination-inhibition test for antibodies formed in response to Mycoplasma gallisepticum. Avian Dis 32:262-72
Bencina D, Tadina T, Dorrer D. 1988. Natural infection of ducks with Mycoplasma synoviae and Mycoplasma gallisepticum and myocplasma egg transmission. Avian Pathol 17:441-9.

Charlton BR, Bickford AA, Chin RP, Walker RL. 1999. Randomly amplified polymorphic DNA (RAPD) analysis of Mycoplasma gallisepticum isolates from turkeys from the central valley of California. J Vet Diagn Invest 11:40815.

Feberwee A, Mekkes DR, de Wit JJ, Hartman EG, Pijpers A. 2005a. Comparison of culture, PCR, and different serologic tests for detection of Mycoplasma gallisepticum and Mycoplasma synoviae infections. Avian Dis 49:260-8.

Feberwee A, Mekkes DR, Klinkenberg D, Vernooij J, Gielken A, Stegeman J. 2005b. An experimental model to quantify horizontal transmission of Mycoplasma gallisepticum. Avian Pathol 34:355-61.

Fritz BA, Thomas CB, Yuill TM. 1992. Serological and microbial survey of Mycoplasma gallisepticum in wild turkeys Meleagridis galloparo from six western states. JWildlife Dis 28:10-20.

Gatesa AE, Frascaa S, Nyaokeb A, Gortona TS, Silbart LK, Geary SJ. 2008. Comparative assessment of a metabolically attenuated Mycoplasma gallisepticum mutant as a live vaccine for the prevention of avian respiratory mycoplasmosis. Vaccine 26:2010-9.

Higgins PA, Whithear KG. 1985. Detection and differentiation of M. gallisepticum and M. synoviae antibodies in chicken serum using enzyme-linked immunosorbent assay. Avian Dis 30:160-8.

Hong Y, Garcı'a M, Levisohn S, Lysnyansky I, Leiting V, Savelkoul PHM, Kleven SH. 2005. Evaluation of amplified fragment length polymorphism for differentiation of avian Mycoplasma species. J Clin Microbiol 43:90912.

Jordan FTW, Mustafa A. 1983. Preliminary studies on the ELISA in examining chicken turkey and quail sera for antibodies to avian mycoplasma. Yale J Biol Med 56:854.

Levisohn S, Kleven SH. 2000. Avian Mycoplasmosis (Mycoplasma gallisepticum). Rev Sci Tech 19:425-42.

Miles AA, Misra SS. 1938. The estimation of the bacterial power of the blood. J Hyg 38:732-48.

Mettifogo E, Buzinhani M, Buim MR, Piantino Ferreira AJ, Kleven SH, Timenetsky J. 2006. Molecular characterization of MG isolates using RAPD and PFGE isolated from chickens in Brazil. J Vet Med B 53:445-50.

Nascimento ER, Pereira VLA, Nascimento MGF, Barreto ML. 2005. Avian mycoplasmosis update. Rev Bras Cienc Avic 7:1-9.

Patten BE, Higgins PA, Whithear KG. 1984. A urease-ELISA for detection of mycoplasma infection in poultry. Aust Vet J 61:151-5.

Roberts DH, Olesiuk OM. 1967. Serological studies with M. synoviae. Avian Dis 11:104-9.

Sahy SP, Olsen NO. 1981. Characterisation of an isolate of mycoplasma WVU 907 which possesses common antigens to M. gallisepticum. Avian Dis 25 4:943-53.

Salami JO, Addo P, Umoh JU, Adegboye DS. 1992. Chicken mycoplasmosis: a review with special reference to $M$. gallisepticum and M. synoviae. Vet Bull 62:511-20.

Soeripto, 2009. [Chronic Respiratory Disease (CRD) in Chicken] [in Indonesian]. Wartazoa 3:134-42.

Stakenborg T, Vicca J, Butaye P, Maes D, Baere TD, Verhelst R, Peeters J, de Kruif A, Haesebrouck F, Vaneechoutte M. 2005. Evaluation of amplified rDNA restriction analysis (ARDRA) for the identification of Mycoplasma species. BMC Infect Dis 5:46, doi: 10.1186/14712334-5-46.

Talkington FD, Kleven SH, Brown J. 1984. An enzyme-linked immunosorbent assay for the detection of antibodies to Mycoplasma gallisepticum in experimentally infected chickens. Avian Dis 29:53-70.

Thorns CJ, Boughton E. 1980. Studies on the effect of growth medium composition on the antigenicity of Mycoplasma bovis. J Hyg 84:29-36.

Timms LM. 1967. Isolation and identification of avian mycoplasma. J Med Lab Technol 24:78-89. 
Timms LM, Cullen GA. 1974. Detection of Mycoplasma synoviae infection in chickens and its differentiation from Mycoplasma gallisepticum infection. British Vet J 130:75-84.
Weisburg WG, Tully JG, Rose DL, Petzel JP, Oyaizu H, Yang D, Mandelco L, Sechrest J, Lawrence TG, Van Etten J, Maniloff L, Woese CR. 1989. A pylogenetic analysis of the mycoplasmas: basis for their classification. J Bacteriol 171:6455-67. 